\title{
SCREENING TESTS ARE NOT ENOUGH TO DETECT HEMINEGLECT
}

\author{
Manuel Alvim Leite Lopes', Hebert Pereira Ferreira', \\ Juliana Costa Carvalho', Lídia Cardoso', Charles André
}

\begin{abstract}
Objective: To verify the sensitivity of the conventional subtests of the Behavioral Inattention Test (BIT) in the diagnosis of hemineglect after stroke. Method: One hundred and two patients with cerebral infarct or hemorrhage were prospectively evaluated. In 22, hemineglect was diagnosed using standard BIT criteria. The frequency of hemineglect using 6 commonly used screening subtests of this battery was assessed. Results: Hemineglect would not be recognized in 10 patients if they were only screened using the line crossing test; this would be the case in 2 patients with the letter cancellation test; and in 4 patient with the line bisection test. Three patients would not be diagnosed even if both line crossing and line bisection tests were used. Conclusion: Hemineglect may not be recognized with single screening tests commonly used. The use of a standard battery is recommended to improve diagnostic sensitivity in individuals with various subtypes of hemineglect.
\end{abstract}

KEY WORDS: perceptual disorders, hemispatial neglect, stroke, diagnosis.

\begin{abstract}
Testes de triagem não são suficientes para diagnosticar heminegligência
RESUMO - Objetivo: Verificar a sensibilidade dos subtestes convencionais da Behavioral Inattention Test (BIT) no diagnóstico da heminegligência após o acidente vascular cerebral (AVC). Método: Foram avaliados prospectivamente 102 pacientes com AVC. Em 22 casos heminegligência foi diagnosticada através do BIT. A freqüência de diagnóstico correto utilizando os 6 subtestes específicos desta bateria foi analisada. Resultados: 10 pacientes não seriam diagnosticados como heminegligentes se fossem avaliados apenas com o "line crossing", 2 se o teste de triagem escolhido fosse o "letter cancellation", e 4 se utilizássemos apenas o "line bisection". Além disso, 3 pacientes não teriam recebido o diagnóstico correto mesmo utilizando dois testes usuais de triagem - "line crossing" e "line bisection". Conclusão: O uso de testes isolados de triagem pode falhar em diagnosticar heminegligência após o AVC. O uso de uma bateria formal de avaliação é necessário para identificar indivíduos com diferentes tipos de heminegligência.
\end{abstract}

PALAVRAS-CHAVE: transtornos da percepção, heminegligência, acidente cerebrovascular, diagnóstico.

After a stroke, patients may exhibit impairments of countless types and combinations ${ }^{1}$. Hemineglect, a cognitive-behavioral syndrome, is caracterized by an attention defict ${ }^{2}$ and is common following stroke ${ }^{3}$. It has been defined as a failure to report, orient oneself toward, or respond to stimuli on the contralesional side that cannot be attributed solely to sensory or motor dysfunction 4 . Unilateral neglect doesn't come in a uniform way, however, being constituted by a series of symptoms and manifestations in different combinations ${ }^{5}$. Hemineglect is much more frequent after a cortical or subcortical lesion of the right hemisphere ${ }^{6}$. The varied nature of this syndrome makes its identification and evaluation a complex task. Neglect can be assessed by several tests as the Cancellation tests $^{7-9}$, Line Bisection ${ }^{10}$, Drawing and Copying tests ${ }^{7}$, Imagery test ${ }^{11}$, reading of texts, description of objects and scenes, and functional tasks. Line Bisection, Cancellation Test, Representational Drawing test and the Figure and Shape Copying test are called "pencil and paper tests" and are more frequently used because they are simple and fast to administer.

Because of its marked clinical variability, hemineglect should not be evaluated by a single test ${ }^{22}$; the use of a battery of tests that evaluates all hemineglect types is thus recommended. The test battery

'Mestrando do Programa de Pós-Graduação em Clínica Médica, Setor Neurologia, Universidade Federal do Rio de Janeiro, Rio de Janeiro RJ, Brazil (UFRJ); ${ }^{2}$ Professora Adjunta do Departamento de Psiquiatria da Faculdade de Medicina da UFRJ, Doutora em Ciências da Saúde-Programa de Pós Graduação em Psiquiatria e Saúde Mental/IPUB/UFRJ; 3Professor Adjunto do Departamento de Clínica Médica, Setor Neurologia, da Faculdade de Medicina da UFRJ.

Received 19 March 2007, received in final form 4 September 2007. Accepted 19 September 2007.

Dr. Chalés André - Serviço de Neurologia 10E36 / Universidade Federal do Rio de Janeiro / Hospital Universitário Clementino Fraga Filho (HUCFF) - Avenida Rodolpho Paulo Rocco 255 - Cidade Universitária - Ilha do Fundão - 21941-913 Rio de Janeiro RJ - Brasil. Email: dr.charles.andre@gmail.com 
more commonly used to evaluate unilateral neglect is the Behavioural Inattention Test (BIT) ${ }^{7}$.

We studied the sensitivity of the conventional subtests of the BIT to diagnose hemineglect after stroke.

\section{METHOD}

We submitted patients with stroke to a wide investigation of hemineglect using the conventional part of the BIT and we compared the sensibility of the whole battery, according to the cutoff stipulated by its authors, with each test alone. The objective was to verify the sensitivity of the conventional subtests of the BIT to diagnose hemineglect after stroke.

One hundred and two patients with right hemisphere ischemic or hemorrhagic stroke occurring at least three months before assessment were evaluated prospectively in the period of January 2006 to December 2006. Time since stroke varied from 3 to 131 months. Twenty-two patients with hemineglect confirmed by the conventional sub-tests of BIT and with a neuroimaging confirmatory exam were included. Patients with significant stroke-related motor or communication impairment precluding task understanding or execution were excluded, as well as individuals with comorbidities such as Parkinson's disease, dementia or other degenerative diseases of the central nervous system (CNS).

Table 1. Characteristics of included patients with hemineglect.

\begin{tabular}{|c|c|c|c|c|}
\hline Patient & Gender & $\begin{array}{l}\text { Age } \\
\text { (years) }\end{array}$ & $\begin{array}{c}\text { Time from } \\
\text { onset (months) }\end{array}$ & $\begin{array}{c}\text { Formal } \\
\text { education (years) }\end{array}$ \\
\hline 1 & $\mathrm{~F}$ & 56 & 5 & 4 \\
\hline 2 & $M$ & 54 & 34 & 12 \\
\hline 3 & $M$ & 72 & 3 & 1 \\
\hline 4 & $\mathrm{~F}$ & 63 & 9 & 5 \\
\hline 5 & $\mathrm{~F}$ & 73 & 39 & 5 \\
\hline 6 & $M$ & 57 & 4 & 5 \\
\hline 7 & $\mathrm{~F}$ & 55 & 8 & 0 \\
\hline 8 & $\mathrm{~F}$ & 63 & 10 & 12 \\
\hline 9 & $\mathrm{~F}$ & 67 & 36 & 5 \\
\hline 10 & $M$ & 64 & 36 & 12 \\
\hline 11 & $\mathrm{~F}$ & 49 & 3 & 9 \\
\hline 12 & $M$ & 46 & 3 & 12 \\
\hline 13 & $M$ & 62 & 4 & 20 \\
\hline 14 & $M$ & 73 & 4 & 16 \\
\hline 15 & $\mathrm{~F}$ & 80 & 4 & 16 \\
\hline 16 & $M$ & 73 & 74 & 16 \\
\hline 17 & $\mathrm{~F}$ & 73 & 4 & 5 \\
\hline 18 & $\mathrm{~F}$ & 72 & 131 & 12 \\
\hline 19 & $M$ & 63 & 5 & 5 \\
\hline 20 & $\mathrm{~F}$ & 73 & 12 & 7 \\
\hline 21 & $M$ & 65 & 11 & 5 \\
\hline 22 & $M$ & 68 & 23 & 5 \\
\hline
\end{tabular}

M, Male; F, Female
The conventional subtests of $\mathrm{BIT}^{7}$ are the Line Crossing, Letter Cancellation, Star Cancellation, Line Bisection, Figure and Shape Copying and Representational Drawing. The maximum score in the conventional BIT is 146; patients that present scores below 129 are considered to have hemineglect. However, each subtest has a specific cutoff suggested by the authors; hence, the performance in the total battery was compared with that in each subtest. All patients included in the study were right handed, with age varying from 46 to 80 years (Table 1 ).

The Mcnemar test was used to compare the sensitivity of the conventional subtests of the BIT failing to diagnose diagnostic neglect in at least one case. A p value $<0.05$ was stipulated as statistically significant. The software SPSS (version 13.0 for Windows) was used for statistics analysis.

This study was approved by the research ethics committee of the institution, and all patients agreed to participate and signed the consent form.

\section{RESULTS}

One hundred and two patients with right hemisphere stroke were assessed. Twenty-two patients $(21.6 \%)$ were considered hemineglect by the total BIT score. All 22 hemineglect patients presented neglect in the Star Cancellation, in the Figure and Shape Copying and in the Representational Drawing. However, some patients would not be considered hemineglect if only some other subtests were done (Table 2). Ten patients would not be diagnosed if only assessed with Line Crossing, two with the Letter Cancellation, and four with the Line Bisection. Futhermore, three patients would not be considered hemineglect, even if both Line Crossing and Line Bisection tests were the only tests used.

A significant difference was only observed between Line Crossing and Letter Cancellation ( $p=0.03$ ). No significant difference was found between Line Crossing and Line Bissection ( $p=0.07$ ) or between Letter Cancellation and Line Bisection $(p=0.68)$. The test was not applicable to Star Cancellation, Figure and Shape Copying and Representational Drawing because they had $100 \%$ sensitivity.

\section{DISCUSSION}

Hemineglect patients present a worse outcome following stroke $\mathrm{e}^{13}$. Stroke severity and the presence of unilateral neglect are independently related to a worse prognosis in activities of daily living (ADL), greater morbidity and lethality rates, and prolonged hospital stay ${ }^{14}$. Different types of neglect exist, which vary according to the lesion location ${ }^{15}$. The syndrome can be classified according to the primarily impaired system: sensory neglect, motor neglect (action and intention disorder of movement), and representacional 
Table 2. Results in diverse subtests of the Behavioral Inattention Test (BIT)

\begin{tabular}{|c|c|c|c|c|c|c|c|}
\hline Patients & $\begin{array}{l}\text { Line }^{1} \\
\text { crossing }\end{array}$ & $\begin{array}{l}\text { Letter }^{2} \\
\text { cancellation }\end{array}$ & $\begin{array}{c}\text { Star }^{3} \\
\text { cancellation }\end{array}$ & $\begin{array}{c}\text { Figure }^{3} \\
\text { shape copying }\end{array}$ & $\begin{array}{c}\text { Line }^{4} \\
\text { Bisection }\end{array}$ & $\begin{array}{l}\text { Drawing }^{3} \\
\text { test }\end{array}$ & $\begin{array}{c}\text { BIT } \\
\text { (total) }\end{array}$ \\
\hline 1 & $\mathrm{~N}$ & Y & $Y$ & $Y$ & $Y$ & Y & 112 \\
\hline 2 & $Y$ & Y & $Y$ & $Y$ & $\mathrm{~N}$ & $Y$ & 88 \\
\hline 3 & $Y$ & Y & Y & Y & Y & Y & 37 \\
\hline 4 & $\mathrm{~N}$ & Y & Y & $Y$ & $Y$ & Y & 70 \\
\hline 5 & $Y$ & Y & Y & $Y$ & $Y$ & Y & 78 \\
\hline 6 & $Y$ & Y & $Y$ & $Y$ & $Y$ & Y & 27 \\
\hline 7 & $\mathrm{~N}$ & Y & $Y$ & Y & Y & Y & 50 \\
\hline 8 & $\mathrm{~N}$ & Y & Y & Y & $\mathrm{N}$ & Y & 119 \\
\hline 9 & $Y$ & Y & Y & $Y$ & $Y$ & Y & 86 \\
\hline 10 & $\mathrm{~N}$ & Y & Y & Y & $Y$ & $Y$ & 83 \\
\hline 11 & $\mathrm{~N}$ & Y & $Y$ & Y & $N$ & Y & 112 \\
\hline 12 & $Y$ & Y & $Y$ & Y & $Y$ & Y & 44 \\
\hline 13 & $Y$ & Y & Y & $Y$ & $Y$ & Y & 48 \\
\hline 14 & $Y$ & Y & Y & $Y$ & $Y$ & Y & 38 \\
\hline 15 & $Y$ & Y & Y & Y & $Y$ & Y & 89 \\
\hline 16 & $Y$ & $\mathrm{~N}$ & $Y$ & Y & $Y$ & Y & 103 \\
\hline 17 & $Y$ & $\mathrm{~N}$ & Y & $Y$ & $Y$ & Y & 108 \\
\hline 18 & $\mathrm{~N}$ & Y & Y & $Y$ & $Y$ & Y & 102 \\
\hline 19 & $\mathrm{~N}$ & Y & Y & $Y$ & $\mathrm{~N}$ & $Y$ & 121 \\
\hline 20 & $\mathrm{~N}$ & Y & $Y$ & Y & Y & Y & 91 \\
\hline 21 & $Y$ & $Y$ & $Y$ & $Y$ & $Y$ & $Y$ & 97 \\
\hline 22 & $\mathrm{~N}$ & $Y$ & Y & $Y$ & $Y$ & $Y$ & 95 \\
\hline
\end{tabular}

$\mathrm{Y}$, considered hemineglect; $\mathrm{N}$, not considered hemineglect; 'Significant difference between line crossing and letter cancellation ( $p=0.03 / \mathrm{McNe}-$ mar test); no significant difference between line crossing and Line bissection ( $p=0.07 /$ McNemar Test); ${ }^{2}$ Significant difference between letter cancellation and line crossing ( $p=0.03$ / McNemar test); no significant difference between letter cancellation and line bissection ( $p=0.68 /$ McNemar Test); ${ }^{3}$ Test not applicable; ${ }^{4}$ No significant difference between line bissection and line crossing ( $p=0.07 /$ McNemar Test); or with letter cancellation ( $p=0.68 /$ McNemar Test).

neglect (disorders of mental representation) ${ }^{16}$. Also, it can be classified according to the affected spatial domain in personal and extra-personal neglect ${ }^{17,18}$.

In our study, using the cut-off value stipulated by the authors of $\mathrm{BIT}^{7}, \mathbf{2 1 . 6 \%}$ of stroke patients in the present series were considered hemineglect. Those results are in agreement with data obtained by a metaanalysis ${ }^{19}$ in which the hemineglect frequency varied from 13 to $82 \%$ after right hemisphere lesions.

Our study confirms that the use of a single test to diagnose hemineglect may prove somewhat insensitive and inappropriate, with potentially serious consequences resulting from not addressing patients' individual rehabilitation needs, as hemineglect patients frequently fail to improve with conventional treatments ${ }^{13}$. However, our results suggest that Star Cancellation, Figure and Shape Copying and Representational Drawing can be useful and sensitive to diagnose the syndrome.
According to Azouvi and coworkers ${ }^{20}$, the sensitivity of the Cancellation Test varies according to the presence or absence of symbols diverting patients' attention and with the inclusion of simple or double targets. Star Cancellation includes symbols to divert the attention, while in Line Crossing (Albert test) those distracters are not included. The Letter Cancellation includes both distracters and double targets. Our results therefore confirm that the presence of distracters is an important factor increasing the diagnostic sensitivity, as all patients with neglect diagnosed in BIT would also be recognized using Star Cancellation, with only 2 exceptions if the Letter Cancellation were used. Why exactly the Letter Cancellation was less frequent to detect hemineglect than Star Cancellation in the present study is unknown, but this could be related to its structured form. Ten patients would not be recognized with Line Crossing. Previous reports disagree as to the relative sensitivity of Cancellation tests and the Line Bisection ${ }^{21,22}$. A possible reason for 
this discrepancy is the difference between diverse Cancellations tests used. In our study, 3 versions of the Cancellation test were used: Line Crossing, Letter Cancellation and Star Cancellation. The sensitivity of these different versions varied markedly. Four patients were not negligent in Line Bisection. The detection of hemineglect with this test was more frequent than with Line Crossing but less frequent than the Letter Cancellation and Star Cancellation tests. It should be highlighted that cancellation tests and line bisection cannot be used to differentiate motor and sensitive neglect, as both require visual and manual exploration ${ }^{23}$.

All patients with hemineglect in the BIT were detected by the Figure and Shape Copying and by the Representational Drawing Test. Although both tests use similar tasks, they evaluate different components of hemineglect. Figure and Shape Copying assesses sensorial and motor neglect but is unable to distinguish types of neglects because it requests visual and manual exploration simultaneously. On the other hand, the Representational Drawing Test evaluates representational and motor neglect but is unable to distinguish types of neglect, since it simultaneously requires manual exploration and intact internal representation. Previous reports highlight problems in the use and interpretation of Figure and Shape Copying Test and Representational Drawing Test. The interpretation is somewhat subjective ${ }^{24 ;}$ also, cognitive impairments could also alter their results ${ }^{25}$; the two tests may also exhibit low sensitivity when compared with "Star Cancellation" and "Line Bisection" (57.5\% and $76.4 \%$ respectively) ${ }^{21}$. However, even considering the subjectivity of result interpretation and the possible confounding effect of cognitive impairments, our results did not confirm the low sensitivity of the tests as previously reported.

In summary, hemineglect can appear and be classified in several ways. It does not constitute a unitary syndrome, but a complex set of signs and symptoms. It is related with worse clinical course after stroke. Its detection and evaluation may be a complex task, and the use of single tests can fail to diagnose hemineglect following stroke. The use of a formal evaluation battery is necessary to identify individuals with different types of hemineglect.

\section{REFERENCES}

1. Riddoch MJ, Humphreys GW, Bateman A. Cognitive deficits following stroke. Physiotherapy 1995;81:465-473.

2. Swan L. Unilateral spatial neglect. Phys Ther 2001;81:1572-1580.

3. Plummer P, Morris ME, Dunai J. Assessement of unilateral neglect. Phys Ther 2003;83:732-740.

4. Heilman KM, Watson RT, Valenstein E. Neglect and related disorders. In Heilman KM, Valenstein E (Eds). Clinical neuropsychology. 3.Ed. New York: Oxford University Press, 1993;279-336.

5. Pierce SR, Buxbaum LJ. Treatments of unilateral neglect: a review. Arch Phys Med Rehabil 2002;83:256-268.

6. Vallar G. The anatomical basis of spatial neglect in humans. In Robertson IH, Marshall JC (Eds). Unilateral neglect: clinical and experimental studies. Hove, UK: Lawrence Erlbaum associates publishers 1993:27-59.

7. Wilson BA, Cockburn J, Halligan PW. Behavioural inattention test. Titchfield, Hants, England: Thames Valley Test Company Ltd. 1987.

8. Albert ML. A simple test of visual neglect. Neurology 1973;23:658-664.

9. Wilson BA, Cockburn J, Halligan PW. Development of a behavioral test of visuospatial neglect. Arch Phys Med Rehab 1987;68:98 -102.

10. Marsh NV, Kersel DA. Screening tests for visual neglect following stroke. Neuropsychol Rehab 1993;3:245-257.

11. Bisiach E, Luzzatti C. Unilateral neglect of representational space. Cortex 1978;14:129-133.

12. Azouvi P, Samuel C, Louis-Dreyfus A, et al. Sensitivity of clinical and behavioural tests of spatial neglect after right hemisphere stroke. J Neurol Neurosurg Psychiatry 2002;73:160 -166.

13. Paolucci S, Antonucci G, Grasso MG, Pizzamiglio L. The role of unilateral spatial neglect in rehabilitation of right brain-damaged ischemic stroke patients: a matched comparison. Arch Phys Med Rehab 2001;82:743-749.

14. Paolucci S., Antonucci G.,Gialloreti LE et al. Predicting stroke in patient rehabilitation outcome: the prominent role of neuropsychological disorders. Eur Neurol 1996;36:358-390.

15. Mesulam MM. The multiplicity of neglect phenomena. Neuropsychol Rehab 1994;4:173-176.

16. Mesulam M M. Spatial attention and neglect: parietal, frontal and cingulated contributions to the mental representation and attentional targeting of salient extrapersonal events. Phil Trans R Soc Lond B 1999;354:1325-1346.

17. Beschin N, Robertsom IH. Personal versus extrapersonal neglect: a group study of their dissociation using a reliable clinical test. Cortex 1997;33:379-384

18. Halligan PW, Marshall JC. Left neglect for near but not far space in man Nature 1991;350:498-500.

19. Bowen A, Mckenna K, Tallis RC. Reasons for variability in the reported rate of occurrences of unilateral spatial neglect after stroke. Stroke 1999;30:1196-1202.

20. Azouvi P, Marchel F, Samuel C, et al. Functional consequences and awareness of unilateral neglect: study of an evaluation scale. Neuropsychol Rehab 1996;6:133-150.

21. Black SE, Vu B, Martin D, Szalai J. Evaluation of a bedside battery for hemispatial neglect in acute stroke [abstract]. J Clin Exp Neuropsychol 1990;12:109.

22. Bailey MJ, Riddoch MJ, Crome P. Evaluation of a test battery for hemineglect in elderly stroke patients for use by therapists in clinical practice. Neuro Rehabil 2000;14:139-150.

23. La'davas E. The role of visual attention in neglect: a dissociation between perceptual and directional motor neglect. Neuropsychol Rehab 1994;4:155-159.

24. Agrell BM, Dehlin OI, Dahlgren CJ. Neglect in elderly stroke patients: a comparison of five tests. Psychiatry Clin Neurosci 1997;51:295-300.

25. Lieberman D, Galinsky D, Fried V, et al. Factors affecting the results of the clock drawing test in the elderly patients hospitalized for physical rehabilitation. Int J Geriatr Psychiatry 1999;14:325-330. 